\title{
Evaluation of the outcome of amniotic membrane transplantation for ocular surface reconstruction in symblepharon
}

\begin{abstract}
Aims Symblepharon is a condition that can inflict serious morbidity on the affected patients. Our aim was to evaluate the efficacy of amniotic membrane transplantation in the surgical treatment of symblepharon by determining the rate of epithelization of the graft, the incidence of complications, and the rate of recurrence of cicatrization.

Methods In all, 20 eyes of 18 patients with symblepharon due to various causes and with varied indications for surgery underwent symblepharon excision and amniotic membrane transplantation (AMT).

Results We observed recurrence of symblepharon in eight out of the 20 eyes operated upon, but in two of these the cicatrization was focal in nature and did not afford any functional impairment to the patients. Four out of the six eyes that failed had preoperative severe dry eye, and four had undergone previous conjunctival surgery. Conclusions AMT appears to be a safe and effective procedure for the surgical treatment of symblepharon. We observed a $100 \%$ rate of epithelization of the graft with no significant postoperative complications and a $30 \%$ rate of cicatrization. Pre-existing dry eye and previous conjunctival surgery influence the success of the surgery and these eyes may need medical or surgical supplementation along with AMT to limit the amount of subconjunctival fibrosis for better surgical results.

Eye (2004) 18, 1251-1257. doi:10.1038/sj.eye.6701379

Published online 30 April 2004
\end{abstract}

Keywords: amniotic membrane; symblepharon; dry eye

S Jain and A Rastogi

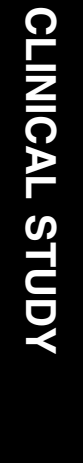

\section{Introduction}

Symblepharon is a condition with a diverse aetiology ranging from injuries and infections to oculocutaneous disorders and drugs. Whatever the cause, it can impose a significant amount of morbidity upon the patient in the form of persistent lacrimation, diminution of vision, double vision or foreign body sensation. In these eyes, it becomes imperative to treat the symblepharon to restore the normal ocular surface.

A variety of approaches have been tried for the successful surgical management of chronic symblepharon. ${ }^{1-14}$ However, none of these have met with unreserved success due to the various associated complications. ${ }^{2-13}$

Various materials have been evaluated as substitutes for ocular surface epithelia following excision of the symblepharon. A popular alternative was the use of mucus membrane grafts obtained from the buccal cavity, nose, hard palate, and maxillary sinus for the above purpose. However, these suffer from the disadvantages of difficulty in harvesting, limited availability, persistence of reddish colour long after surgery, and unacceptable complications at the donor site..$^{2-10,15,16}$

Nonporous PTFE has been explored as an alternative, as it does not have a limitation of size, is chemically and biologically inert, and resistant to infection. However, it is associated with a relatively high extrusion rate $(\sim 20 \%)$ and may permit proliferation of submucous fibrous tissue in cicatricial inflammatory diseases, leading to eventual failure. ${ }^{11}$

Postoperative subconjunctival fibrosis has been identified as the commonest cause of failure of the surgery and recurrence of the
Guru Nanak Eye Centre Maharaja Ranjit Singh Marg New Delhi, India

Correspondence: S Jain, MS, MRCOphth Kings College Hospital Denmark Hill London SES 9RS

E-mail: drsaurabhjain@ hotmail.com

Received: 23 May 2003 Accepted: 6 November 2003

Published online: 30 April 2004

We certify that this work has not been submitted or been previously published in any other journal. No grants or sponsorships have been requisitioned for this study. The authors do not have any commercial interest in any product or procedure mentioned in this manuscript.

This work has been presented in part at the $\mathrm{XX}$ Congress of the European Society of Cataract and Refractive Surgeons, Nice 711 September 2002 and the VI Ophthalmological Conference of SAARC Countries held in Kathmandu, Nepal, November 19-21, 1999. 
symblepharon. Beta irradiation and antimitotic agents have been used both intra- and postoperatively to reduce this fibrotic response. However, specific indications, regimens, and delivery systems for their use have not been established. Moreover, they have been associated with serious complications including scleral necrosis and delayed epithelization. ${ }^{12,13}$

Amniotic membrane transplantation (AMT) is a relatively recent approach to the surgical management of chronic symblephera. The basis of its use rests on unique properties of the membrane, which have shown to be beneficial in this scenario. ${ }^{12}$

The amnion serves as 'transplanted basement membrane' acting as a new healthy substrate suitable for proper epithelization. This basement membrane helps migration of epithelial cells, reinforces adhesion of basal epithelial cells, promotes epithelial differentiation, and prevents epithelial apoptosis. ${ }^{17-19}$ The membrane has been successfully used for culturing rabbit oral mucosal cells $^{20}$ as well as corneal/limbal epithelium for transplanting in patients with limbal deficiency. ${ }^{21}$

The membrane produces various growth factors including basic fibroblast growth factor, hepatocyte growth factor, and transforming growth factor $\beta$ (TGF $\beta)^{12}$ that can stimulate epithelization ${ }^{22-24}$ and act as promoters of epithelization and inhibit protease activity.

Amniotic membrane does not express HLA-A, B or DR antigens and hence immunological rejection does not occur after its transplantation. ${ }^{23,24}$

In addition it has antifibroblastic properties as it induces a downregulation of TGF $\beta$ signalling, responsible for fibroblastic activation in wound healing. ${ }^{25,26}$ This leads to an inhibition and arrest in fibroblast proliferation, following contact with normal substrate, and prevents the occurrence of subconjunctival fibrosis, which is usually the cause of recurrence of symblephera after surgery.

In addition, it becomes indistinguishable from subconjunctival tissue, once covered with conjunctiva, thus offering excellent cosmesis. It forms a continuous collagenous sheet on the sclera and functions as a mechanical barrier, keeping potentially adhesive surfaces apart.

These properties have prompted the use of these membranes in patients with ocular chemical and thermal burns, ${ }^{27}$ recurrent pterygia associated with symblepharon, ${ }^{28}$ after pterygium excision, in corneal surface reconstruction, ${ }^{12}$ revision of leaking blebs after glaucoma surgery, ${ }^{29-31}$ bullous keratopathy, ${ }^{32}$ after surgical treatment of band keratopathy, ${ }^{33}$ symptomatic conjunctivochalsis, ${ }^{34}$ ulceration of the cornea and sclera, ${ }^{35}$ post excimer to reduce corneal haze, ${ }^{36,3}$ etc, and more recently for the treatment of symblepharon. ${ }^{38}$
Our aim was to study the results of amniotic membrane transplantation in the surgical treatment of symblepharon, to determine the rate of re-epithelization of the amniotic membrane graft, assess incidence of the intra- and postoperative complications encountered, and to observe the recurrence rate of cicatrization following AMT in these eyes.

\section{Materials and methods}

A total of 20 eyes of 18 patients were operated upon in this interventional, noncomparative, prospective study. All eyes included presented with stage II or III symblepharon (Tauber's ${ }^{14}$ staging) of varied aetiology, including chemical, thermal, and mechanical injuries, congenital, iatrogenic or post-surgical, and symblephera secondary to oculocutaneous syndromes or ocular cicatrizing disorders.

Patients with acute infection or inflammation at the operative site, those with active Stevens-Johnson's syndrome (SJ syndrome) or pemphigoid, patients with Stage I symblepharon, ${ }^{14}$ and those presenting with ankyloblepharon were excluded from the study.

In all the patients selected, a detailed preoperative ocular and systemic evaluation was undertaken, including an assessment of the ocular motility, diplopia charting, and staging of the symblepharon by Tauber's ${ }^{14}$ method. The presence of dry eye, if any, was documented (defined as a Schirmer's value less than $5 \mathrm{~mm}$ after $15 \mathrm{~min}$ ). The indication for which the patient was booked for surgery was also noted.

\section{Preparation of the membrane}

The placental membranes were obtained from mothers seronegative for Hepatitis B, and C, Syphilis, and HIV at elective caserean section. The translucent amnion was separated from the underlying thick, vascular chorion and preserved at $+4^{\circ} \mathrm{C}$ by the method outlined by Dino et al. ${ }^{39}$ A marking 6-0 silk suture was used to differentiate the rough mesenchymal from the smooth epithelial surface. All membranes obtained were used within $24 \mathrm{~h}$ and precautions were taken to keep the membrane and the media sterile at all times.

\section{Surgical procedure}

Surgery was performed under either general or peribulbar anaesthesia.

The eye to be operated was cleaned and draped and adequate exposure obtained with a lid speculum.

The conjunctiva was incised horizontally along the ends of the symblepharon and undermined from the 
Tenon's fascia to allow the tissue to retract to its normal anatomical position. The adjacent extraocular muscles were identified and hooked. The subconjunctival fibrous tissue was excised to the maximum extent possible and any adhesions with the muscle sheaths were released. The exposed sclera was lightly cauterized. Corneal involvement was cleared by superficial keratectomy with a diamond knife.

An amniotic membrane graft, approximately $20 \%$ larger than the corresponding conjunctival defect, was obtained from the preserved membranes. The graft was placed epithelial side up on the scleral surface and secured to the recipient conjunctival edge with $8 / 0$ Vicryl sutures. Care was taken to anchor the graft to the bed with episcleral sutures. Fornix-forming sutures with $4 / 0$ silk were used in selected eyes.

The eye was patched postoperatively and the pad removed the next day. The patient started on topical Ofloxacin every $4 \mathrm{~h}$ in the operated eye. Topical prednisolone acetate $1 \%$ every other hour was commenced once the corneal epithelial defect healed (confirmed by fluorescein staining). These drops were continued for 2 weeks and then tapered off over the next few weeks.

The fornix-forming sutures were removed after 3 weeks.

\section{Postoperative evaluation}

The patients were reviewed on the immediate postoperative day, weekly for the first 3 weeks and then monthly till the end of 1 year.
The parameters assessed at every visit included the best-corrected visual acuity, ocular motility, and diplopia charting, evaluation of the lid margin contour, and the presence of postoperative inflammation or infection.

The graft was evaluated with respect to its position, colour, degree of epithelization, and the presence or absence of subconjunctival fibrosis.

Recurrence of the symblepharon (if any) was documented and staged at every visit.

Any significant postoperative complications were recorded.

Successful outcome of the surgery was defined as a healthy fully epithelized graft area with no recurrence of the symblepharon (or recurrence of a stage lesser than or equal to IIa) at the completion of follow-up, affording no functional or cosmetic disability to the patient.

\section{Results}

The study group comprised 20 eyes of 18 patients, all of whom underwent symblepharon excision with AMT. The mean age was 26.3 years (10-70) and the sex ratio, 11 males to seven females. The demographics and the clinical data of the patients are summarized in Table 1.

The common causes included recurrent pterygium (five), acid burns (one), alkali burns (five), Stevens Johnson (SJ) syndrome (four), thermal burns (three), and congenital symblephera (two).

The indications for surgery were diplopia (two), as a prerequisite for penetrating keratoplasty (eight), entropion (five), squint (two) mechanical ptosis (one),

Table 1 Clinical and demographic data.

\begin{tabular}{|c|c|c|c|c|c|c|c|c|}
\hline $\begin{array}{l}\text { Agel } \\
\text { Sex }\end{array}$ & Aetiology & $\begin{array}{l}\text { Previous } \\
\text { surgery }\end{array}$ & Indication & $\begin{array}{c}\text { OM } \\
\text { restriction }\end{array}$ & $\begin{array}{c}\text { Pre Op } \\
\text { Symblepharon }\end{array}$ & $\begin{array}{c}\text { Schirmers } \\
(\mathrm{mm})\end{array}$ & Recurrence & Outcome \\
\hline $70, \mathrm{M}$ & Recurrent pterygium & 2 & DIPLOPIA & ++ & III(1)a & 18 & $\mathrm{II}(1) \mathrm{a}$ & $S$ \\
\hline $10, \mathrm{M}$ & Congenital & 0 & PRE PK & ++ & $\mathrm{II}(1) \mathrm{a}$ & 18 & & $S$ \\
\hline $10, \mathrm{M}$ & Congenital & 0 & PRE PK & ++ & III(1)a & 15 & & $S$ \\
\hline $24, \mathrm{M}$ & Acid Burn & 0 & ENTROPION & ++ & $\mathrm{II}(1) \mathrm{b}$ & 25 & & $S$ \\
\hline $55, \mathrm{M}$ & Recurrent pterygium & 0 & ENTROPION & 0 & $\mathrm{III}(1) \mathrm{b}$ & 25 & & $S$ \\
\hline $12, \mathrm{~F}$ & Alkali burn & 0 & COSMETIC & + & $\mathrm{II}(1) \mathrm{a}$ & 17 & & $S$ \\
\hline $25, \mathrm{~F}$ & SJ syndrome & 1 & ENTROPION & + & III(1)d & 12 & & $S$ \\
\hline $19, \mathrm{M}$ & Recurrent pterygium & 5 & DIPLOPIA & ++ & $\mathrm{II}(1) \mathrm{a}$ & 17 & III(1)a & $\mathrm{F}$ \\
\hline $19, \mathrm{~F}$ & SJ syndrome & 1 & COSMETIC & 0 & III(1)b & 0 & $\mathrm{II}(1) \mathrm{C}$ & $\mathrm{F}$ \\
\hline $18, \mathrm{M}$ & Thermal burn & 2 & ENTROPION & ++ & $\mathrm{II}(1) \mathrm{C}$ & 16 & & $S$ \\
\hline $15, \mathrm{M}$ & SJ syndrome & 0 & PRE PK & +++ & III(1)d & 0 & $\mathrm{III}(1) \mathrm{C}$ & $\mathrm{F}$ \\
\hline $15, \mathrm{M}$ & SJ syndrome & 0 & PRE PK & +++ & III(1)d & 0 & $\mathrm{III}(1) \mathrm{C}$ & $\mathrm{F}$ \\
\hline $10, \mathrm{M}$ & Alkali burn & 1 & PTOSIS & + & $\mathrm{II}(1) \mathrm{b}$ & 9 & $\mathrm{II}(1) \mathrm{b}$ & $\mathrm{F}$ \\
\hline $19, \mathrm{~F}$ & Mechanical & 0 & PRE PK & + & $\mathrm{II}(1) \mathrm{C}$ & 12 & & $S$ \\
\hline $60, \mathrm{~F}$ & Recurrent pterygium & 1 & SQUINT & ++ & $\mathrm{II}(1) \mathrm{a}$ & 17 & $\mathrm{II}(1) \mathrm{a}$ & $S$ \\
\hline $14, \mathrm{M}$ & Thermal burn & 0 & PRE PK & + & III(1)a & 22 & & $S$ \\
\hline $70, \mathrm{M}$ & Recurrent pterygium & 2 & SQUINT & ++ & III(1)a & 17 & & $S$ \\
\hline $10, \mathrm{~F}$ & Alkali burn & 1 & PRE PK & + & III(1)a & 15 & & $S$ \\
\hline
\end{tabular}

+: mild ocular movement restriction; ++: moderate ocular movement restriction; +++: severe ocular movement restriction. 
and cosmetic (two). Out of the total operated eyes, 10 (ie 50\%) had been operated one or more times previously.

On initial examination, four patients had a Schirmer's I value less than $5 \mathrm{~mm}$ in $10 \mathrm{~min}$, signifying a dry eye, the cause being SJ syndrome in three and thermal burns in one patient. Two patients complained of double vision preoperatively due to associated restrictive strabismus.

After surgery, the amniotic graft re-epithelized completely in all eyes, beginning at the edges of the graft at a mean time period of 15.5 days (12-18) and completely covering the graft in a mean time period of 23.3 days (20-27). The regenerated conjunctiva was indistinguishable from the surrounding conjunctival epithelium on slit-lamp examination.

The immediate postoperative period in most eyes was largely unremarkable with a rapid decline in the amount of postoperative inflammation, as evidenced by diminishing conjunctival congestion and chemosis. However, four eyes (20\%) showed signs of persistent inflammation lasting beyond 2 weeks, which necessitated vigorous anti-inflammatory therapy in the form of frequent topical steroid drops (prednisolone acetate hourly) for the first 2 weeks and then tapered gradually.

One patient who had been operated upon five times in the same eye previously for recurrent pterygium showed an exuberant fibroblastic response with complete recurrence of the symblepharon as early as 3 weeks postoperatively. We obtained a biopsy from the edge of the graft to study the nature of the response.

The histopathological evaluation revealed mild to moderate acute on chronic inflammation of the transplanted amniotic membrane. The newly proliferated conjunctiva showed areas of congestion with neovascularization and fibrosis (Figures 1-7).

No graft was rejected in our mean observation period of 53.3 weeks (32-80 weeks).

We noticed a significant improvement in ocular motility in $100 \%$ (18) of the patients with restricted preoperative movements, and complete remission of diplopia in all the patients (two) complaining of it preoperatively.

We did not observe a statistically significant improvement in visual acuity after surgery due to the poor corneal transparency in the eyes that were undergoing preparatory symblepharon release before penetrating keratoplasty.

We observed recurrence of symblepharon in eight out of the 20 eyes operated $(40 \%)$.

However, in two of these patients, the recurrence was of stage IIa that did not pose any functional problems for the patient. Thus, our failure rate was only $30 \%$.

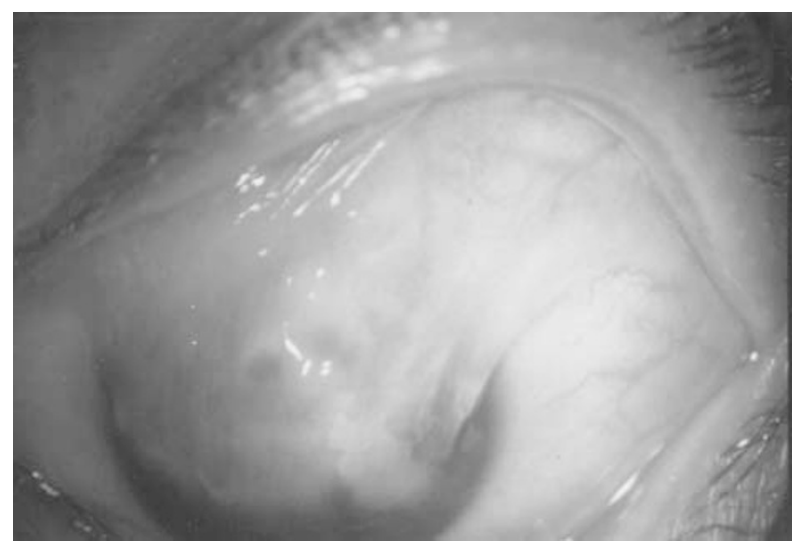

Figure 1 Preoperative photograph showing a patient with an anterior staphyloma and Stage III(c) symblepharon following mechanical injury.

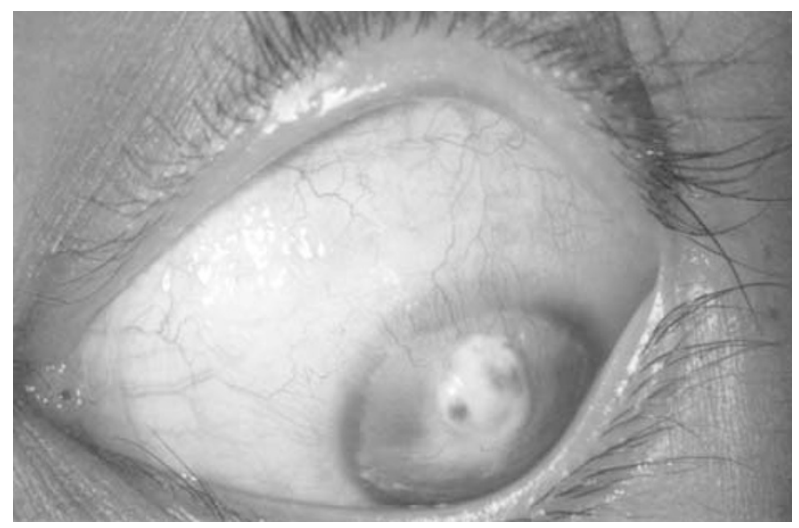

Figure 2 Postoperative clinical photograph at 6 months showing healthy well-epithelized graft with no recurrence of the symblepharon. The patient subsequently underwent an optical penetrating keratoplasty.

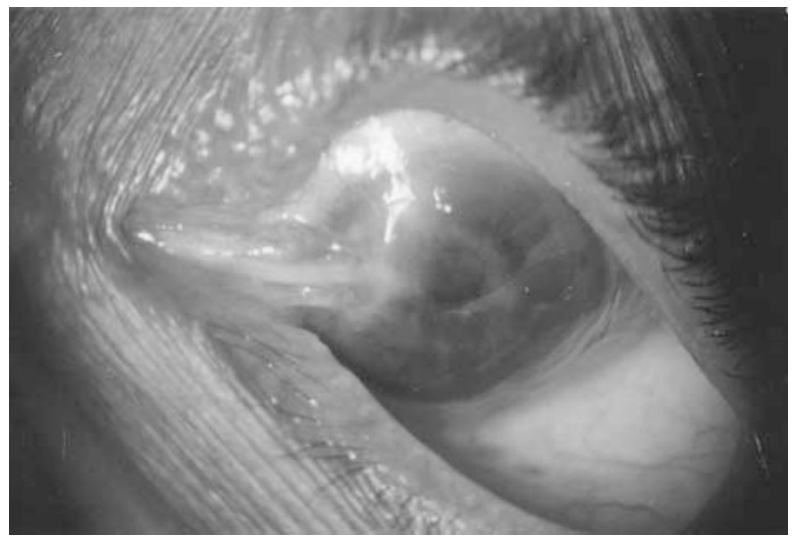

Figure 3 A medial symblepharon that formed following pterygium excision and led to severe restriction of ocular motility and binocular diplopia. 


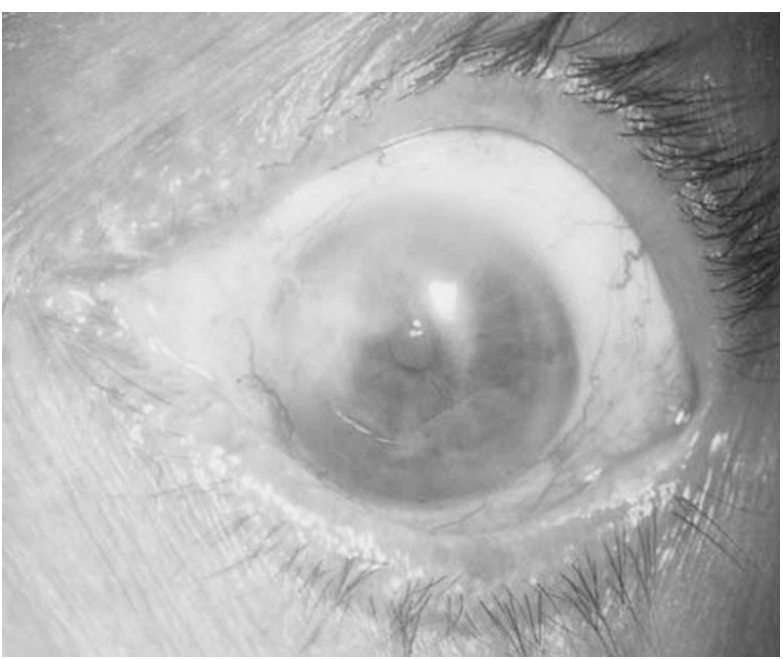

Figure 4 Postoperative photograph at 6 weeks, with marked improvement in ocular motility and no diplopia.

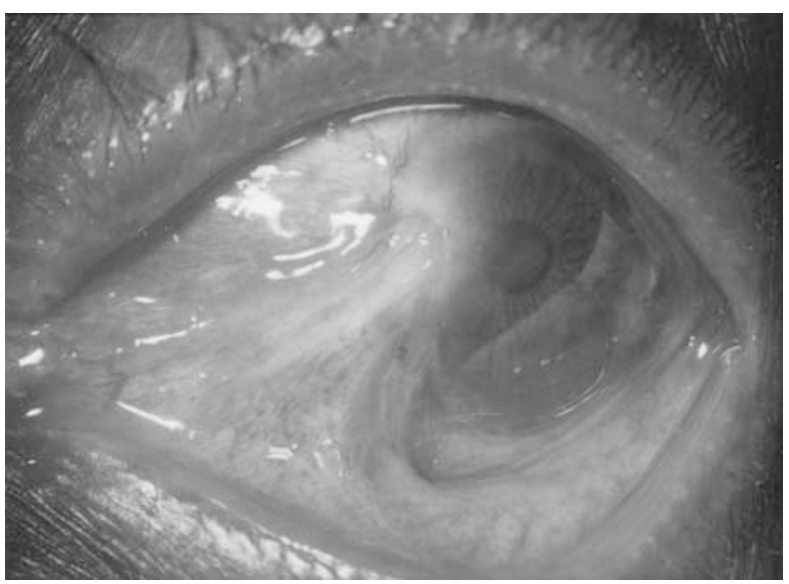

Figure 5 Recurrent pterygium Stage III b(1) symblepharon with two previous corrective surgeries.

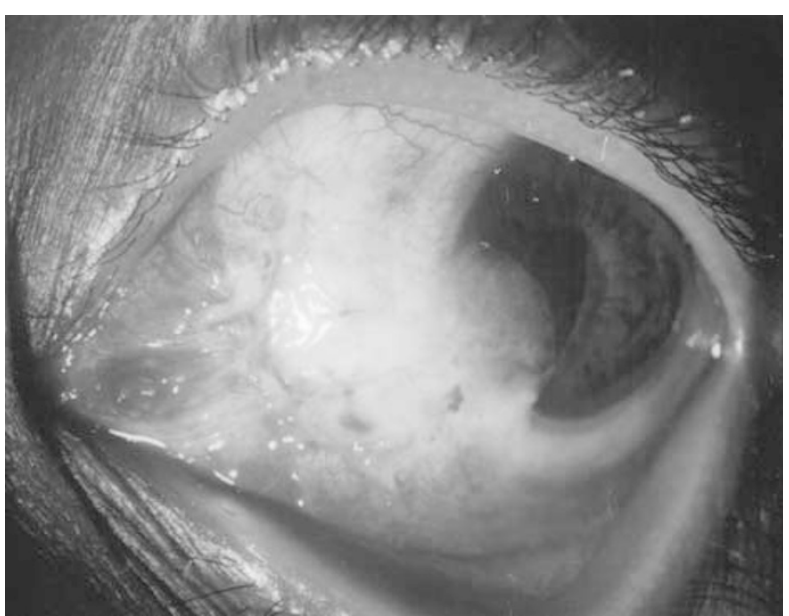

Figure 6 The same patient as Figure 5, 2 weeks postoperatively, with partial re-epithelization of the graft.

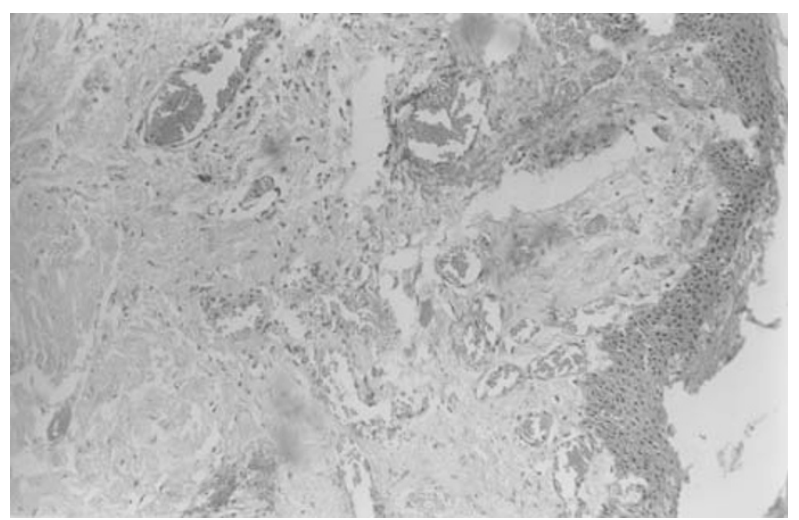

Figure 7 Photomicrograph showing severely inflamed conjunctival epithelium with vascularization, hyalinization, and subconjunctival fibrosi.

All (four) the eyes that had documented dry eye preoperatively failed and four of the six eyes that failed had been operated on at least once earlier.

\section{Discussion}

The use of amniotic membrane in the reconstruction of conjunctival surface is not a novel concept, with the earliest reports dating back to the $1940 \mathrm{~s} .{ }^{40}$ However, after ensuing decades of relative obscurity, interest has resurfaced again in the use of amniotic membrane in the treatment of ocular surface disorders. ${ }^{41-43}$ We evaluated the outcome of AMT for reconstruction of the conjunctival surface following surgical treatment of chronic symblephera in 20 eyes of 18 patients in our study.

In our study, the surgical outcome of AMT after symblepharon excision was fair with only six eyes out of the 20 operated failing to meet the criteria for a successful surgical outcome as defined in the protocol.

All the patients who had preoperative severe dry eye (four), that is, Schirmer's value less than $5 \mathrm{~mm}$ in $15 \mathrm{~min}$ responded very poorly to the surgery with a $100 \%$ failure rate. Three of these eyes belonged to patients suffering from SJ Syndrome and one secondary to extensive thermal injury, both of which caused extensive damage to the ocular surface and disruption of the tear film. It has been demonstrated previously that decreased tear secretion is a significant risk factor of surgical failure in SJ Syndrome, with a failure rate of $68.4 \%$ that compared with $100 \%$ in our study. ${ }^{44}$

Preoperative tear function is a strong determinant for successful ocular surface construction, as tears are essential for the proliferation and differentiation of epithelial cells. ${ }^{44}$ Tears have been shown to contain many important epithelial modifying factors, such as epidermal growth factor, ${ }^{45}$ vitamin $\mathrm{A}^{46}$ and TGF $\beta$ - 1 and 
$\beta$-2. Decreased tear production not only causes desiccation, but also nutritional deprivation in ocular surface epithelia and accumulation of cytotoxic components in the ocular surface.

The amniotic membrane provides only a basement membrane for epithelial proliferation, but cannot replace the tear film, which may explain the high rate of failure in these eyes. Thus, it acts as a substrate but not as substitute for healthy conjunctiva.

All of these eyes exhibited an intense and prolonged postoperative inflammatory response. The failure in these eyes may thus also be related to the elaboration of collagenases as a result of the inflammation that can cause early degradation of the amniotic membrane before epithelization is complete.

Measures used to manage ocular surfaces in patients with deficient tear films postoperatively include autologous serum eye drops, hyaluronic acid eye drops, and punctual occlusion. However, no prospective study has conclusively proved the superiority of any one method over the others.

A contributory factor determining the success of the procedure appeared to be previous conjunctival surgery. Four of the six eyes that failed and six out of the eight eyes that recurred had previous conjunctival surgery though there seemed to be no statistically significant correlation between the severity of postoperative fibrotic response and the number of previous surgeries. The recurrence in these eyes was probably due to a greater subconjunctival fibroblastic response that led to eventual recurrence of the symblepharon.

We conclude that AMT after symblepharon release is a safe and effective procedure with a $100 \%$ rate of epithelization and no significant postoperative complications. We observed a $30 \%$ rate of failure, the success of the surgery being limited by the underlying ocular pathology, and previous surgical profile. Patients suffering from severe preoperative dry eye or those who have undergone multiple previous conjunctival surgery may not be best suited to AMT alone, but may need a supplementary medical or surgical procedure.

\section{References}

1 Fein W. Repair of total and subtotal symblepharons Ophthalmic Surg 1979; 10: 44-47.

2 Shore JW, Foster CS, Westfall CT, Rubin PA. Results of buccal mucosal grafting for patients with medically controlled ocular cicatricial pemphigoid. Ophthalmology 1992; 99: 383-395.

3 Bartley GB, Kay PP. Posterior lamellar eyelid reconstruction with a hard palate mucosal graft. AJO 1989; 107: 609-612.

4 Cohen MS, Shorr N. Eyelid reconstruction with hard palate mucosa grafts. Ophthalmic Plast Reconstr Surg 1992; 8: 183-195.
5 Manner GE, Mathers WD, Wofley DE, Martinez JA. Hard palate mucosa graft in Stevens-Johnson syndrome. Am J Ophthalmol 1994; 118: 786-791.

6 Siegel RJ. Palatal grafts for eyelid reconstruction. Plast Reconstr Surg 1985; 76: 411-414.

7 Wood CI. Readily available full thickness mucous membrane graft. Arch Otolaryngol Head Neck Surg 1987; 113: 770-771.

8 Kuckelkorn R, Redbrake C, Schrage NF et al. Autologus transplantation of nasal mucosa after severe chemical and thermal eye burns. Klin Monatsbl Augenheilkd 1994; 204: $155-161$.

9 Naumann GO, Lang GK, Rummelt V, Wigand ME. Autologus nasal mucosa transplantation in severe bilateral conjunctival mucus deficiency syndrome. Ophthalmology 1990; 97: 1011-1017.

10 Kuckelhorn R, Schrage N, Redbrake C, Kottek A, Ram M. Autologus transplantation of nasal mucosa after severe chemical and thermal eye burns. Acta Ophthalmol Scand 1996; 74(5): 442-448.

11 Levin PS, Dutton JJ. Polytetrafluroethylene alloplastic grafting as a substitute for mucous membrane. Arch Ophthalmol 1990; 108: 282-285.

12 Shimazaki J, Shinozaki N, Tsubota K. Transplantation of amniotic membrane and limbal autograft for patients with recurrent pterygium associated with symblepharon. $\mathrm{Br} \mathrm{J}$ Ophthalmol 1998; 82: 235-240.

13 Secchi AG, Tognon MS. Intraoperative Mitomycin C in the treatment of cicatricial obliteration of conjunctival fornices. Am J Ophthalmol 1996; 122: 728-730.

14 Tauber J, Jabbeur N, Foster S. Improved detection of disease progression in ocular cicatricial pemphigoid. Cornea 1992; 11: $446-451$.

15 Neuhas RW, Baylis HI, Shorr N. Complications at mucous membrane donor sites. AJO 1982; 93: 643-646.

16 Tseng SCG, Li D-Q, Ma X. Down regulation of TGF- B1, B2, $\mathrm{B} 3$ and TGG -B receptor II expression in human corneal fibroblasts by amniotic membrane. Invest Ophthalmol Vis Sci 1998; 39: S248.

17 Guo M, Grinell F. Basement membrane and human epidermal differentiation in vitro. J Invest Dermatol 1989; 93: 372-378.

18 Boudreau N, Sympson CJ, Werb Z, Bussell MJ. Supression of ICE and apoptosis in mammary epithelial cells by extracellular matrix. Science 1995; 267: 891-893.

19 Robson MC, Krizek TJ. effect of human amniotic membranes on the bacterial population of infected rat burns. Ann Surg 1973; 177: 144.

20 Nakamura T, Endo K, Cooper LJ, Fullwood NJ, Tanifuji N, Tsuzuku M et al. The successful culture and autologous transplantation of rabbit oral mucosal epithelial cells on amniotic membrane. Invest Ophthalmol Vis Sci 2003; 44(1): 106-116.

21 Shimazaki J, Aiba M, Goto E, Kato N, Shimmura S, Tsubota K. Transplantation of human limbal epithelium cultivated on amniotic membrane for the treatment of severe ocular surface disorders. Ophthalmology 2002; 109(7): 1285-1290.

22 Robson MC, Krizek TJ, Koss N, Samburg JL. Amniotic membranes as temporary wound dressing. Surg Gynaecol Obstet 1973; 136: 904.

23 Trelford-Saunder M, Trelford JD. Replacement of the peritoneum with amnion following pelvic exenteration. Surg Gynaecol Obstet 1977; 145: 699. 
24 Shimazaki J, Yung HY, Tsubota K. Amniotic membrane transplantation for ocular surface reconstruction in patients with chemical and thermal burns. Ophthalmology 1997; 104: 2068-2076.

25 Terranova VP, Lyall RM. Chemotaxis of human gingival epithelial cells to laminin. A mechanism for epithelial cell apical migration. J Periodontol 1986; 57: 311-317.

26 Talmi YP, Sigler L, Inge E. Antibacterial properties of human amniotic membranes. Placenta 1991; 12: 285-288.

27 Sridhar MS, Bansal AK, Sangwan VS, Rao GN. Amniotic membrane transplantation in acute chemical and thermal injury. Cornea Centre, L.V. Prasad Eye Institute, Hyderabad, India. Am J Ophthalmol 2000; 130(1).

28 Azuara- Blanco A, Pillai CT, Dua HS. Amniotic membrane transplantation for ocular surface reconstruction. $\mathrm{Br} J$ Ophthalmol 1999; 83(4): 399-402.

29 Fujishima H, Shimazaki J, Shinozaki N et al. Trabeculectomy with the use of amniotic membrane for uncontrollable glaucoma. Ophthalmic Surg Lasers 1988; 29: 428-431.

30 Azuara-Blanco A, Katz LJ. Dysfunctional filtering blebs. Surv Ophthalmol 1998; 43: 93-126.

31 Budenz DL, Barton K, Tseng SC. Amniotic membrane transplantation for repair of leaking glaucoma filtering blebs. Am J Ophthalmol 2000; 130(5): 580-588.

32 Pires RT, Tseng SC, Prabhaswat P et al. Amniotic membrane transplantation for symptomatic bullous keratopathy. Arch Ophthalmol 1999; 117(10): 1291-1297.

33 Anderson DF, Prabhasawat P, Alfonso E, Tseng SC. Amniotic membrane transplantation after the primary surgical management of band keratopathy. Cornea 2001; 20(4): 354-361.

34 Meller D, Maskin SL, Pires RT, Tseng SC. Amniotic membrane transplantation for symptomatic conjunctivochalasis refractory to medical treatments. Cornea 2000; 19(6): 796-803.

35 Hanada K, Shimazaki J, Shimmura S, Tsubota K. Multilayered amniotic membrane transplantation for severe ulceration of the cornea and sclera. Am J Ophthalmol 2001; 131(3): 324-331.

36 Wang MX, Gray TB, Park WC, Prabhasawat P, Culbertson $\mathrm{W}$, Forster $\mathrm{R}$ et al. Reduction in corneal haze and apoptosis by amniotic membrane matrix in excimer laser photoablation in rabbits. J Cataract Refract Surg 2001; 27(2): 310-319.

37 Woo HM, Kim MS, Kweon OK, Kim DY, Nam TC, Kim JH. Effects of amniotic membrane on epithelial wound healing and stromal remodelling after excimer laser keratectomy in rabbit cornea. Br J Ophthalmol 2001; 85(3): 345-349.

38 Solomon A, Espana EM, Tseng SC. Amniotic membrane transplantation for reconstruction of the conjunctival fornices. Ophthalmology 2003; 110(1): 93-100, (14).

39 Dino BR, Eufemio GG, DeVilla MS. The establishment of an amnion bank and it's practical applications in surgery. J Philippine Med Assoc 1966; 42: 357.

40 de Rotth. Plastic repair of conjunctival defects with fetal membranes. Arch Ophthalmol 1940; 23: 522.

41 Chiou AGY, Florakis GJ, Kazim M. Management of conjunctival cicatrizing diseases and severe ocular surface dysfunction. Surv Ophthalmol 1998; 43: 19-46.

42 Tseng SCG, Prabhswat P, Barton K, Greg T, Miller D. Amniotic membrane transplantation with or without limbal autografts for corneal surface reconstruction in patients with limbal stem cell deficiency. Arch Ophthalmol 1998; 116: 431-441.

43 Heligenhaus A, Shore JW, Rubin PAD, Foster CS. Long term results of mucous membrane grafting in ocular cicatricial pemphigoid. Ophthalmology 1993; 100: 1283-1288.

44 Shimazaki J, Shimmura S, Fujishima H, Tsubata K. Association of preoperative tear function with surgical outcome in severe stevens Johnson syndrome. Ophthalmlogy 2000; 107: 1518-1523.

45 Ohashi Y, Motkura M, Kinoshita Y, Mano T, Watanabe M, Kinoshita $\mathrm{S}$ et al. Presence of epidermal growth factor in human tears. Invest Ophthalmol Vis Sci 1989; 30: 1879-1882.

46 Ubels JL, Foley KM, Rismondo V. Retinol secretion by the Lacrimal gland. Invest Ophthalmol Vis Sci 1986; 27: 1261-1268.

47 Shimazaki J, Shinozaki N, Tsubota K. Transplantation of amniotic membrane and limbal autograft for patients with recurrent pterygium associated with symblepharon. $\mathrm{Br} \mathrm{J}$ Ophthalmol 1998; 82: 235-240. 